\title{
PERFORMANCE BASED CODES AND PERFORMANCE BASED FIRE SAFETY DESIGN
}

\author{
Kazunori Harada ${ }^{+}$ \\ Building Research Institute, Ministry of Construction \\ Tatehara 1, Tsukuba, Ibaraki 305-0802, Japan
}

\begin{abstract}
This paper discusses the needs for performance-based approach and its ideal structure in the area of building fire safety. To demonstrate the needs for performance based approach, the limitation of the trade off system was identified using the alternative solutions for smoke vent as an example. Then the desirable structure of the performance-based system is briefly described together with recent development of the evaluation methods associated with performancescale.
\end{abstract}

Key words : performance-based code, fire safety design, objective, functional terms, performance scale, evaluation methods.

\section{INTRODUCTION}

The existing building code describes fire safety provisions such as use of fire safe materials/ construction, limitation of building scale and geometry and so on. This type of codes is called prescriptive as they prescribe the provisions (solution) for fire safety. In a sense, the prescriptive code can be interpreted as a "bible" derived from the experiences in the past. Actually, under the well-updated prescriptive code environment, few problems would arise in the construction of typical buildings.

One of the shortcomings of the prescriptive code is its stiffness. In principle, new materials/ construction/ design methods are hard to be approved if they have some features out of specification package. The performance based (or objective based) approach is a global trend toward 21 st century to re- structure the world of fire safety into flexible system*. The motivations toward the performance-based approach are classified into two aspects.

(1) Adoption of the Rational Methods Based on Engineering Evidence (rationality):

As the buildings are getting larger and complex, empirical methods are becoming relatively less effective to achieve fire safety. On the other hand, rational way to fire safety is feasible based on the knowledge of fire safety engineering.

(2) Fire Safety Technology in Global Economy (accountability):

Due to the spread of global economy, building construction activity is becoming border- less. Not only the building components as well as the design concept and related fire test data are produced in

+ present affiliation : Assoc. Prof., Dept. of Architecture and Environmental Design, Graduate School of Engineering, Kyoto University, Yoshida-Honmachi, Sakyo-ku, Kyoto- 606-0100, Japan

* The trend and present stage of developments are summarized in "Kasai (Nihon Kasai Gakkai-shi), Bulletin of Japan Association for Fire Safety Engineering, Vol. 228 (Feb., 1997) and 232 (Feb., 1998). 
global environment. Prescriptive codes have been developed through the experience of each society. Thus it is hard to correlate the mutual relationships. To encourage the international trade and exchange, performance based approach is necessary. The performance statement is relatively easy to be understood by other society than the prescriptive specifications. This paper discusses the needs for performance based approach in the area of building fire safety and the recent development made through MoC's 5 years project on "Development of the Assessment Method of Fire Safety Performance of Buildings". To encourage the discussion, this paper contains the author's personal opinions rather than official statement.

\section{THE FEATURE OF PRESCRIPTIVE CODES AND NEEDS FOR PERFOR- MANCE BASED CODES}

Before discussing the performance based code, the feature of the prescriptive codes will be summarized. Its limitations will be identified.

\subsection{The Feature of the Prescriptive Code}

Prescriptive code describes the acceptable solution to satisfy the requirements associated with buildings specific to the society. In other words, prescriptive code is a "bible" to design and to construct buildings. The content of the code is daily updated, resulting in a package of acceptable solutions. Thus the prescriptive code is quite convenient to construct a building typical to the society. By following the prescriptive code, all the requirements are automatically satisfied including fire safety, seismic safety, durability and so on without special consideration of mutual relationships.

\subsection{Approval of Alternative Solution "Equivalent" to Preseriptive Solution}

As the prescriptive regulation focuses on definite building type, the applicable range is essentially narrow. If someone hopes to construct a very special building, the prescriptive regulation is sometimes questionable on its effectiveness.

To cover the shortcoming, a prescriptive regulation includes some rules of exception. Building Standards Law of Japan (BSL, hereafter) has an equivalency clause (Article $38^{* *}$ )". By virtue of this article, engineering based fire safety design has been accepted (usually referred to SanPachi system). As the system is getting greater success, limitations are becoming apparent.

Article 38 accepts alternative design solutions that are equivalent to the specifications in the code without specifying the objectives. Lacking the information on the objective, it is sometimes difficult to discuss the equivalency between "specification A" and "specification B".

A simple example is demonstrated exemplifying the natural smoke vent. The objective of the smoke vent is clear as shown in Table 1. The main objectives are (1) evacuation safety and (2) assisting fire fighting and rescue. At the same time, secondary objectives, (3) reduce the risk of

\footnotetext{
** Article 38 in BSL: The provisions of this chapter or those of others or ordinances based thereon shall not apply tuo buildings using special building materials or methods of construction unanticipated thereunder, if the Minister of Construction deems that the said building materials or methods of construction are equal or superior to those specified in the said provisions.
} 
flashover by exhausting hot gases from fire room, (4) prevent the uncontrolled fire spread, are implied. As to the objective (1) and (2), alternative solutions are possible such as positive pressurization smoke control, increase in room volume, and increase in the capacity of egress route. However, the fulfillment of the objective (3) must be discussed in connection with the combustibility of interior linings. Objective (4) shall be discussed with compartmentation. As is demonstrated, the pressurization smoke control does not fully replace the functions of smoke vent. Thus there is nothing like "alternative specification" at least theoretically

Smoke vent can be easily correlated with four functions. However, one specification may correspond with many functions. The alternative specification is hard to be found. That is why we need a performance-based approach.

Table 1. Alternative solutions smoke vent (examples)

\begin{tabular}{|c|c|c|c|c|}
\hline $\begin{array}{l}\text { Prescriptive } \\
\text { solution }\end{array}$ & $\begin{array}{l}\text { Associated } \\
\text { objective }\end{array}$ & \multicolumn{3}{|c|}{ Possible alternative solutions } \\
\hline \multirow{3}{*}{$\begin{array}{l}\text { smoke vent } \\
\text { larger than } \\
1 / 50 \text { of floor } \\
\text { area }\end{array}$} & $\begin{array}{l}\text { (1) evacuation } \\
\text { safety } \\
\text { (2) assisting fire } \\
\text { fighting }\end{array}$ & $\begin{array}{l}{ }^{20} \\
\text { pressurization } \\
\text { smoke control }\end{array}$ & 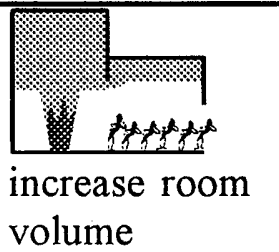 & $\begin{array}{l}\mid \\
\text { increase egress and } \\
\text { access capacity }\end{array}$ \\
\hline & $\begin{array}{l}\text { (3) reduce } \\
\text { flashover } \\
\text { possibility }\end{array}$ & 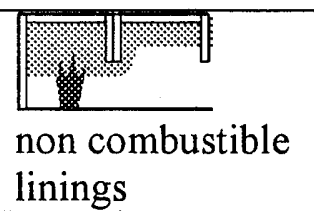 & $\begin{array}{l}\begin{array}{l}\text { automatic ex } \\
\text { system }\end{array} \\
\text { aum }\end{array}$ & xtinguishing \\
\hline & $\begin{array}{l}\text { (4) prevent } \\
\text { uncontrolled } \\
\text { fire spread }\end{array}$ & 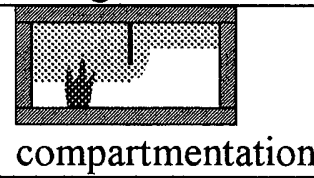 & & \\
\hline
\end{tabular}

\section{PERFORMANCE-BASED CODE FOR BUILDING FIRE SAFETY}

\subsection{Concept}

The fundamental concept of performance based code is shown in Figure 1, in contrast with prescriptive code. In the prescriptive code, a package of specification is described. The package implies fire safety as its intended objective. The goal of building design process is to conform to the package under prescriptive code environment.
In the performance based system, the goals for the fire safety is pointed (Why?). The functional terms (What?) are identified in order to achieve each goal. Then the required level of performance (How?) is described using the performance scale whenever possible. The combination of the fire safety provisions is left to building designers as long as the performance level is sufficient. Under the performance-based environment, the goal of building design process is to conform to the performance 
requirements, not to the specifications.

To move to the performance-based system, the followings are essential.

(1) Explicit Statement of the Fire Safety Goals:

Under the performance-based system, (theoretically) any combination of the fire safety provision is possible as long as performance requirement is satisfied. This will increase the degree of freedom in building construction. To achieve these things, clearly stated fire safety objective is essential in the code. One of the example is a Canadian $\mathrm{OBC}^{\mathrm{l})}$, where they are developing a hierarchy for fire safety.

(2) Introduction of Universal Performance Scale

To get a step ahead, properly selected performance scale is inevitable as a measure to identify the degree of conformance to requirement. If universal performance scale is introduced, and if the contribution by the provisions are properly quantified, combination of the provision is fairly feasible.

Referring the smoke vent as was exemplified previously, several level of performance scale can be determined. For example, in replace with the smoke vent area, smoke exhaust rate can be a performance scale. This scale represents the performance of smoke exhaust under a (specific, possibly) condition. Thus the combination of the provision is possible only as long as the equivalent smoke exhaust performance is achieved.

Climbing up to the upper layer of the performance triangle (Figure 1), smoke exhaust is one of the provisions to assure evacuation safety. In this level, a performance scale can be described by the degree of smoke contamination of the egress routes during evacuation. Using this performance scale, combination of the smoke control system, air tightness of the smoke separation walls/ openings and the capacity of egress routes are possible. As

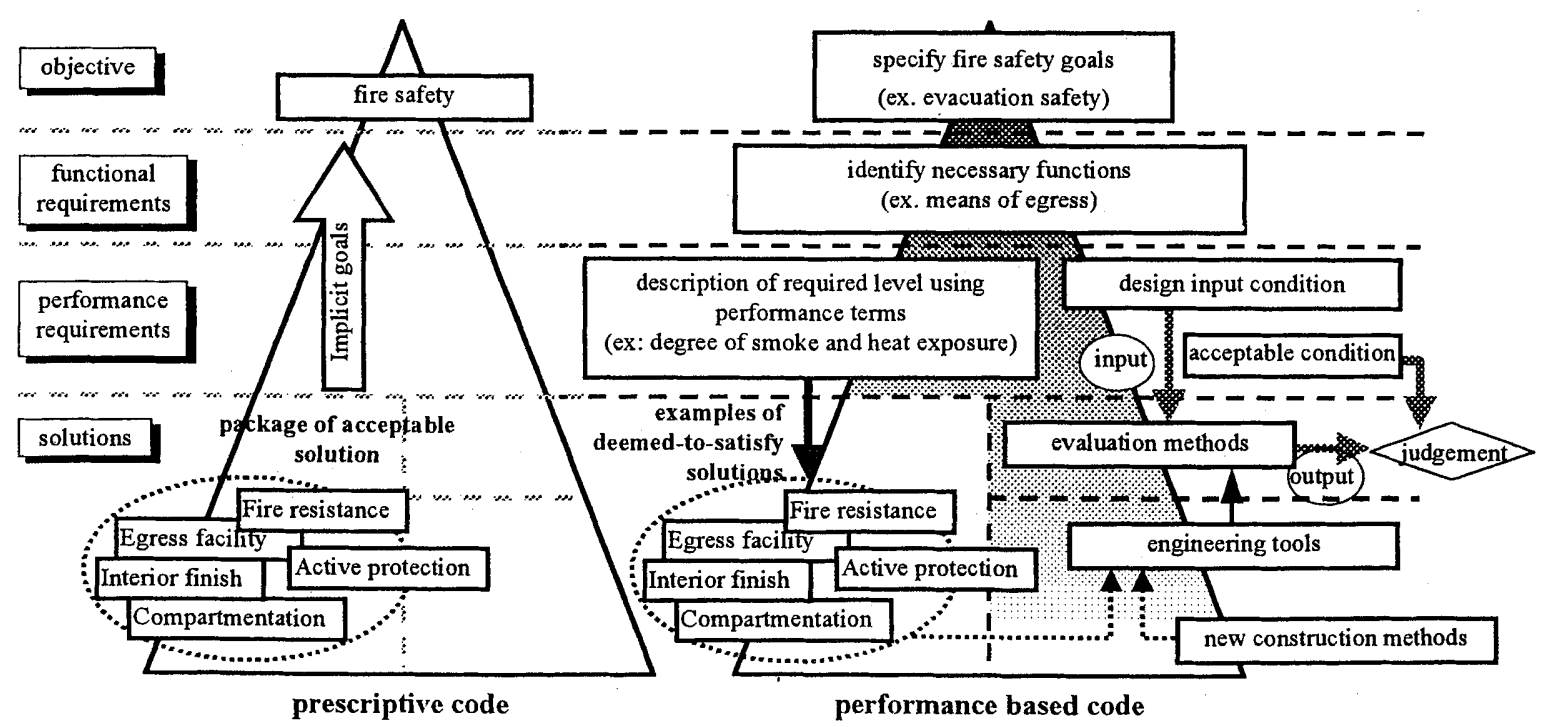

Figure 1. Comparison between prescriptive and performance based system 
was demonstrated in this way, performance scale will have to be established in the upper level as long as possible.

\subsection{Framework}

An example is shown for the performancebased framework of the building fire safety in Figure 2. The framework corresponds with the hatched part in the performance triangle shown in Figure 1. The objective of the fire safety design $(\mathrm{O})$ is summarized into five terms "reduction of fire occurrence", "evacuation safety", "prevention of damage to adjacent properties", "assurance of fire fighting" and "prevention of urban fire". Other objectives are also possible such as property protection. However they are not included here, because the framework intends to cover the area of fire safety provisions in BSL
The functional requirement (R) are determined associated with each objective. Several functional terms may be determined under an objective depending on its nature. For each functional term, required level is described using a performance scale. In this framework, the performance scale is described by using pairs of design fires (F) and corresponding acceptable condition $(\mathrm{J})$. The design fire is similar to seismic wave input used in the seismic resistance design. They are composed of three kinds of fire source. One is the daily heat source $\left(F_{0}\right)$ for the verification of prevention of fire initiation. The second one corresponds with the room fire $\left(F_{1}\right)$ for use in the evacuation safety, prevention of damage to other. property and assurance of fire fighting. Schematic representation is in Figure 3. It start with initial fire growth (typically $t^{2}$ growth + combustion of interior finish, including flashover onset), followed by

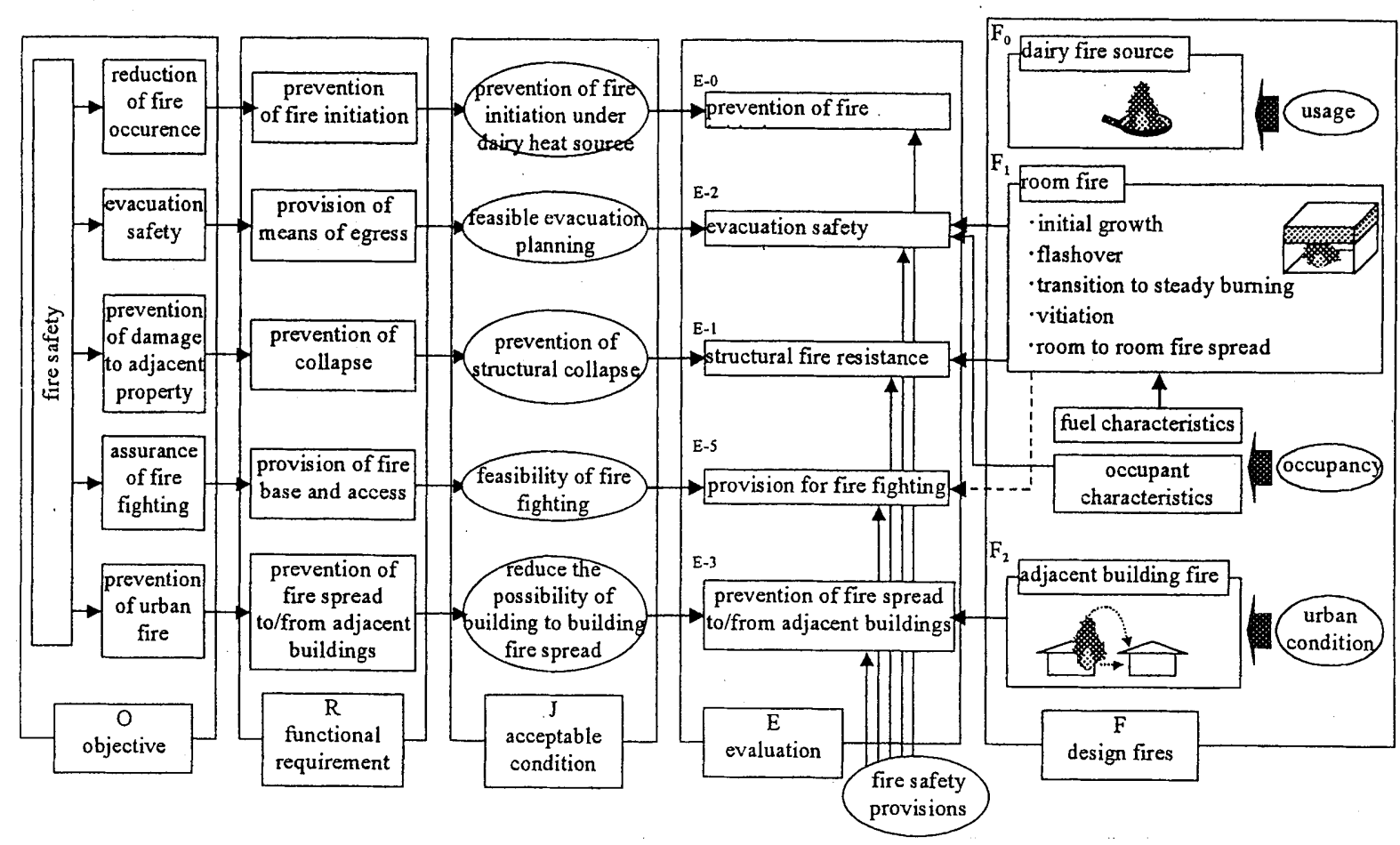

Figure 2. An example of the performance based fire safety design (evaluation) system 


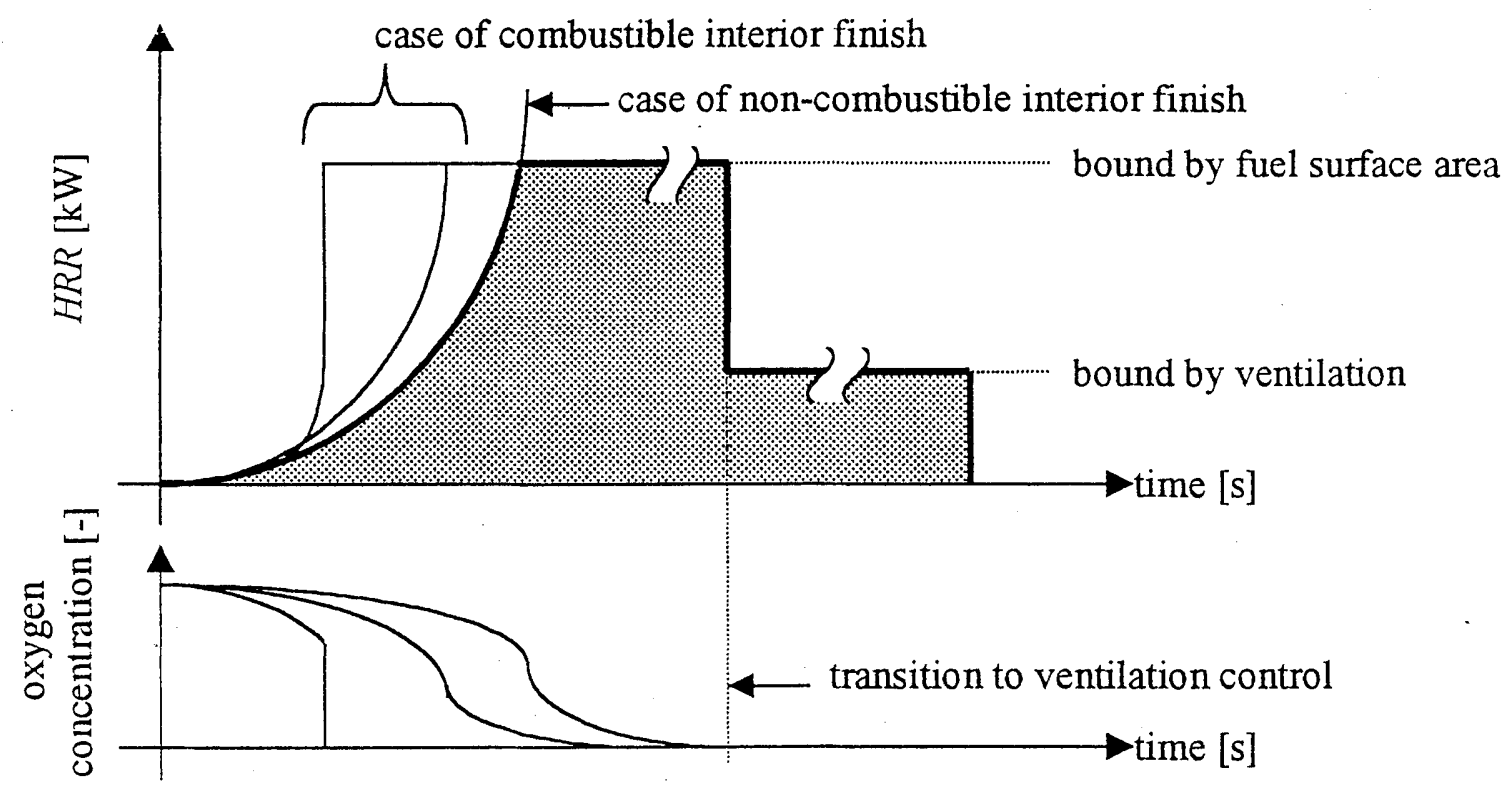

Figure 3. Design fire growth for room fire $\left(\mathrm{F}^{1}\right)$

either fuel surface controlled or ventilation controlled fire ${ }^{2)}$.

Acceptable condition describes the limit state for each functional terms using measurable and/or calculable quantities such as escape time margin, strength reduction and so on.

Evaluation methods (E) is a set of engineering tools to bridge between design fire and acceptable condition. This part advances continuously reflecting new findings of fire engineering knowledge and development of new products. Any validated tools are the candidates of evaluation methods, However a set of simple, hand calculable tools is being developed as a default evaluation method. Using the tools, a pilot case study was carried out for an office building with atrium $^{3)}$ and for a high-rise office building ${ }^{4}$.

\subsection{Example of the Performance Scale} and Evaluation Methods

Among the functional terms, provision of means of egress and the prevention of structural collapse are selected as examples. Performance scale and associated evaluation method is briefly described in this section.

3.3.1 Performance Scale for the Means of Egress and Associated Evaluation Method The functional terms for the means of egress consists of (1) safety from fire phenomena (2) safety from congestion (3) clarity and continuity of the egress routes, and (4) redundancy of the routes (at least one evacuation route regardless of fire location). Among the functions, a performance scale for (1) is discussed in the following.

Figure 4 shows the fire safety provisions associated with safety from fire phenomena. It includes the combustion characteristics of contents (slow, medium, fast), occupant characteristics (awake/ asleep, familiar/ 


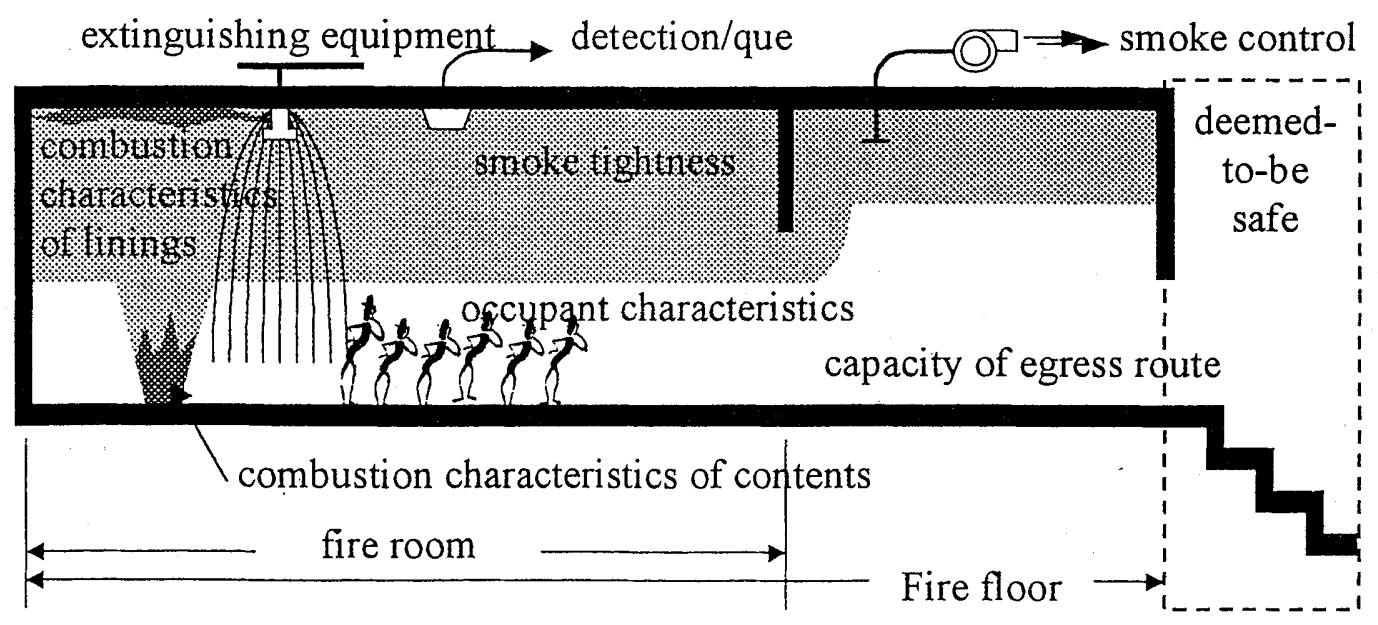

Figure 4. Fire safety provisions associated with "safety from fire phenomena"

unfamiliar, able/ disabled), detection and cue, extinguishers, smoke control and so on. In place of the complete set of provisions, a performance scale can be described by escape time margin $^{5)}$,

$$
M=t_{s}-\left(t_{d}+t_{r}+t_{e}\right)>0
$$

which shall be positive for safe evacuation, where $t_{d}$ is the time to detection [s], $t_{r}$ is the time for initial response [s], $t_{e}$ is the escape movement time [s], and $t_{s}$ is the time to untenable condition (smoke filling) [s].

Closely related to this performance scale, an evaluation tool is being developed as shown in Figure 5. For simplicity, only the evacuation to the staircase is discussed, assuming that the staircase is deemed to be safe. The fire safety provisions can be correlated with the terms in equation (1) as shown in Table 2.

Table 2. Correlation of fire safety provisions with performance scale for safety from fire effect

\begin{tabular}{|c|c|c|}
\hline terms location & Fire room & Non fire rooms \\
\hline Detection time, $t_{d}$ & Sight, Fire detectors & Sight, Alarm and/or speaker \\
\hline Reaction time, $t_{r}$ & $\begin{array}{l}\text { Occupant characteristics } \\
\text { Method of evacuation cue }\end{array}$ & (same provisions as fire room) \\
\hline $\begin{array}{l}\text { Escape movement } \\
\text { time, } t_{e}\end{array}$ & Floor planning, Doorway width & $\begin{array}{l}\text { Floor planning, Doorway width } \\
\text { Distance to Corridor }\end{array}$ \\
\hline $\begin{array}{l}\text { Time to untenable } \\
\text { conditions, } t_{s}\end{array}$ & $\begin{array}{l}\text { Room geometry, Extinguish system, } \\
\text { Smoke control, Fuel characteristics } \\
\text { Interior finish }\end{array}$ & (same provisions as fire room) \\
\hline
\end{tabular}




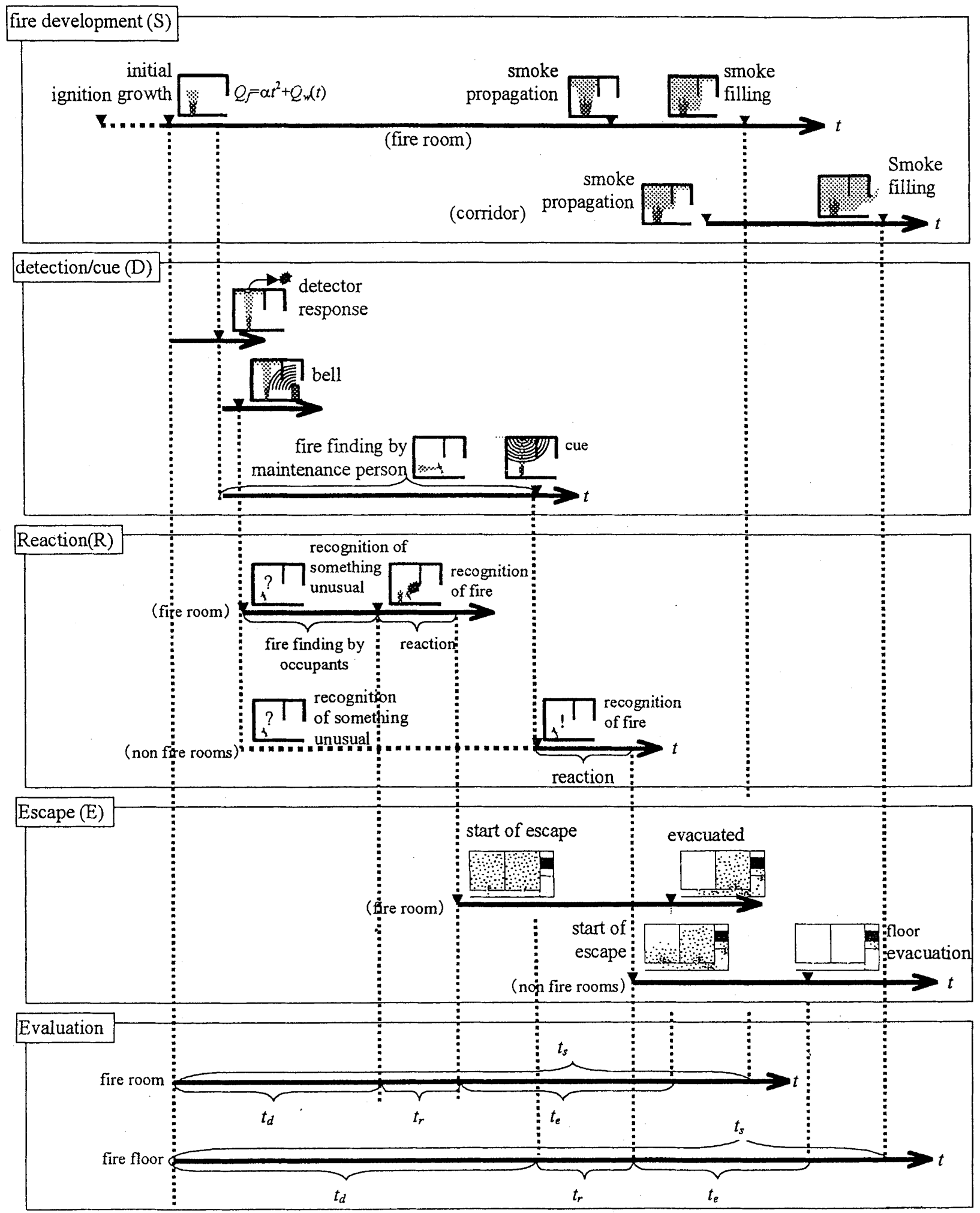

Figure 5. An evaluation tool method of means of egress / safety from fire effect 


\subsubsection{Performance Scale for the Prevention of Structural Collapse}

To prevent the structural collapse, the strength reduction of the load bearing elements shall not fall short of its service load. Namely the margin of strength

$$
M=R-S>0
$$

would be a performance scale. An evaluation method is being developed ${ }^{6}$ taking into account the factors shown in Figure 6.
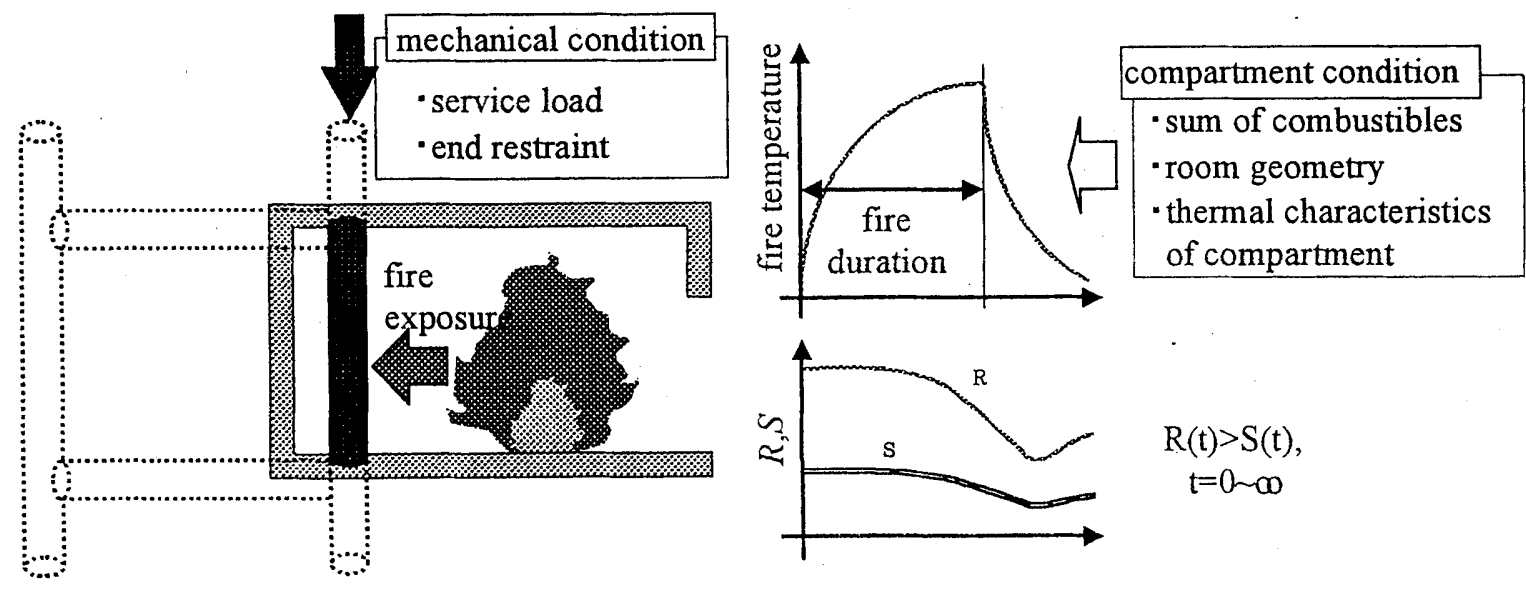

Figure 6. An evaluation method of prevention of collapse

\section{SUMMARY-WHAT WILL CHANGE?}

Performance based code is a regulation whose objective is clearly described with the required level represented by a scale of performance associated with functional terms. In order to move toward the performance based system, rational design methods for fire safety is getting more and more important. A good linkage between code and design methods will expand the room for choice during the building design and construction. At this moment, the following changes are insight.

(1) Rational design for fire safety would be feasible, while the intrinsic safety level unchanged.

(2) Limitations in building geometry will be reduced. This will provide incentives for creation of novel buildings with architects and owners.
(3) The architects and fire engineers are required to develop their own fire safety strategy.

(4) Accountable performance scale and associated evaluation methods will facilitate the import of new technologies beyond the border of society.

To achieve these aspects code and design methods, as well as surrounding environment have to be renewed. The fire community is responsible to design the future of performance based environment.

\section{REFERENCES}

1. Canadian Commission on Building and Fire Codes, "Objective - Based Codes Could Stimulate Innovation", Construction Innovation, spring 1996

2. Hosozawa, T., Tokita, G.', Ohmiya, Y., 
Harada, K., Wakamatsu, T., "Development of the Design Fire Taking into Account the Building Geometry", proc. AIJ Kanto Branch, pp. pp.177-180、1998

3. Tanaka, T, Hokugo, A, Hagiwara, I, Harada, K, Ohmiya, Y., Koya, K., "A Case Study Using the Performance Based Fire safety Design System in Japan", Proceedings of the International Conference on Performance- Based Codes and Fire Safety Design Methods, (Sept., 1996, Ottawa), pp. 409- 420, 1997

4. Tanaka, T., Hagiwara, I., Harada, K., Ohmiya, Y., Mizuno, M., Yamaguchi, J., Tomatsu, T., "Performance- Based Fire Safety Design of a High-rise Office Building", Proceedings of the Second International Conference on Performance- Based Codes and Fire Safety Design Methods, (May., 1998, Maui), (to be published)

5. Magnusson, S., E., Frantzich, H., Harada, K., "Fire Safety Design Based on Calculations: Uncertainty Analysis and Safety Verification", Fire Safety Journal, Vol. 27, pp.305334, 1997

6. Harada, K., Tanaka, T., Morita T., "Rational Framework for Fire Resistance Requirement Based on Relative Risk Concept", Proceedings of the 2nd International Seminar on Fire and Explosion Hazard of Substances, Venting of Deflagrations (Moscow), 1997 